\title{
Current Population Status and Activity Pattern of Lesser Flamingos (Phoeniconaias minor) and Greater Flamingo (Phoenicopterus roseus) in Abijata-Shalla Lakes National Park (ASLNP), Ethiopia
}

\author{
Tewodros Kumssa and Afework Bekele \\ Department of Zoological Sciences, Addis Ababa University, P.O. Box 1176, Addis Ababa, Ethiopia \\ Correspondence should be addressed to Tewodros Kumssa; tewodroskk@gmail.com
}

Received 3 January 2014; Revised 13 February 2014; Accepted 13 February 2014; Published 29 April 2014

Academic Editor: Alexandre Sebbenn

Copyright (C) 2014 T. Kumssa and A. Bekele. This is an open access article distributed under the Creative Commons Attribution License, which permits unrestricted use, distribution, and reproduction in any medium, provided the original work is properly cited.

\begin{abstract}
A study of the population status, habitat preference, and activity pattern of nonbreeding flamingos was carried out in Lakes Abijata, Shalla, and Chitu, part of the Great Rift Valley, Ethiopia, from 2011 to 2013. The current population status and habitat preference of flamingos in the area are still poorly known. Likewise, data on diurnal and seasonal activity pattern of the species are scarce and this leads to the misunderstanding of how Flamingos use local wetlands throughout the different seasons. Data regarding population size and activity pattern were gathered during the wet and dry seasons. Point-count method was used to estimate the population size. Behaviors were recorded using scan sampling techniques. A total of 53671 individuals representing two species of flamingo were counted during both wet and dry seasons from the three lakes. There were more flamingos during the dry season than the wet season in Lake Abijata contrary to Lakes Shalla and Chitu during the wet season. Lesser flamingos (Phoeniconaias minor) were the most abundant species comprising 95.39\%, while Greater Flamingos (Phoenicopterus roseus) accounted for $4.61 \%$ of the total population. Lake Abijata is the major stronghold of Lesser Flamingos in the area. There was significant variation in the mean number of both species during the wet and dry season in the different study sites of the lake, respectively. The species were known to use varied habitats within the lakes. The Lesser Flamingo mainly preferred the shoreline and mudflat areas of the lakes. However, Greater Flamingo on several occasions showed preference to offshore area of the lakes. Seasonal average flock sizes were not similar between the species. There was a strong relationship between time allocated to each activity and time of day. Feeding activity varied among daylight hours and was higher in the evening (76.5\%) and late morning (74.56\%) and least during midday (54\%). Some variations in activity breakdown were observed between time blocks and season. Conservation efforts in the park should include the wild flora and fauna not only of the land but also of the aquatic systems. The information in this study will be very useful for the future management of the species in the area.
\end{abstract}

\section{Introduction}

The hundreds of thousands of flamingos congregating on the African Rift Valley Lakes is one of the truly spectacular sights of the natural word [1]. Sub-Saharan Africa and India are known for their flamingos but the largest flocks occur not only in the East Africa Rift Valley, particularly in the central section at Lakes Bogoria, Elmenteita, Nakuru, and Magadi in Kenya and Natron and Manyara in Tanzania but also at Lakes Rudolf and Abijata in Ethiopia [2, 3] and Lakes Chitu and Shalla of Ethiopia. Additionally, a few thousand individuals occur on Ugandan crater lakes [4], while smaller populations are present in southern Africa (55,000-60,000), West Africa (Mauritania/Senegal) (15,00025,000 ) and 400,0000 individuals occur in the Rann of Kachchh in northwest India $[4,5]$.

Flamingos are one of the most easily recognizable birds, with their long necks and legs, unusual bill shape, and their plumage ranging from pale pink to red or orange with black primary and secondary wing feathers [6]. The amount of 
pink coloration, noticeable particularly on the head and neck, varies greatly amongst individuals, not in relation to age (some birds have a very pink head when otherwise still in immature plumage) but possibly according to diet and an individual's capacity to assimilate carotenes for pigmentation [7]. Lesser flamingos have a highly specialized and fine filter, diet consisting almost entirely of microscopic cyanobacteria and benthic diatoms [8]. However, the Greater Flamingos that occur in the same habitat as the lesser ones (but with lesser density) are generalists consuming copepods, mollusks, annelid worms, small fish, seeds, brine shrimps (Artemisia spp.), and other small planktonic and benthic animals in addition to algae [9].

Of the six species of flamingos in the world, two occur in Africa: the Lesser Flamingo (Phoeniconaias minor) and the Greater Flamingo (Phoenicopterus roseus) [10]. These species overlap in distribution and habitats, occurring mainly in large alkaline or saline lakes, salt pans, and estuaries [11]. Both species are very gregarious and frequently occur in large numbers [12]. The two species mingle freely where they occur, usually at feeding and breeding sites. The Lesser Flamingo is the smallest in size and more numerous in number than the Greater Flamingo one [4]. Both flamingo species are irregular nomadic or partially migratory nomadic and inhabit areas with high seasonal fluctuation in conditions and resources, with a great physical and chemical heterogeneity and geomorphology [13]. Their abundance is associated with variations of water characteristics like conductivity, diversity, and availability of potential food items, alkalinity changes [14], breeding migrations, fresh water requirements and predation pressure [15].

About $60 \%$ of the Greater Flamingo population is located in the Mediterranean region [16]. They occur in lower numbers in Africa. In Eastern Africa, they make up about $1 \%$ of the average number of flamingo aggregations [17]. This species has a very large range, the population trend appears to be increasing, and the population size is very large and hence does not approach the thresholds for vulnerable. So the species is evaluated as of least concern [5].

Greater Flamingos born in France, Spain, and Italy have been observed to breed at other colonies in the Mediterranean and in West Africa, often moving to a third colony thereafter [18]. It has been suggested that the Mediterranean colonies could function as a metapopulation [18]. Following sustained conservation effort undertaken at the two most important breeding colonies in the western Mediterranean (Camargue in France and Fuente de Piedra in Spain), the Greater Flamingo successfully expanded its range in southern Europe and in North and West Africa [19]. Movements between southern Europe and North Africa have long been known [9], and North Africa has generally been considered to be an important wintering ground for Greater Flamingos and a "nursery" for immature flamingos from Europe [20].

However, the Lesser Flamingos are classified by IUCN as being near threatened, due to its dependence on a limited number of unprotected breeding sites, declining of population, and quality of habitat. It is known to breed in only five sites, two in southern Africa (Makgadikgadi Pans in Botswana and Etosha Pan in Namibia), one in east Africa (Lake Natron), and two in India (Zinzuwadia and Purabcheria Salt Pans), and on an artificial island at Kamfers Dam in South Africa. Of these breeding sites, only Etosha Pan and the two sites in India are officially protected [21]. More than $75 \%$ of breeding individuals are concentrated at only one site (Lake Natron, Tanzania) [22]. A narrow range of breeding conditions is required that occur irregularly resulting in a declining population. An irregular episode of mortality involves tens and sometimes hundreds of thousands of birds in East African Rift Valley Lakes [23]. Africa's flamingo populations are not isolated, and flamingos migrate between the Soda lakes of East Africa and the Etosha and Makgadikgadi Pans in southern Africa [10]. Therefore, flamingo conservation should stretch across many political boundaries, and threats to all key habitats need to be considered in an attempt to conserve the African flamingos.

Abijata-Shalla Lake National Park (ASLNP) in Ethiopia is established primarily to conserve the diverse bird life of the area [24]. A great number of bird species seen in these lakes are seasonal migrants; thus the area remains major place of attraction to bird watchers [25]. The Park supports one of the largest African colonies of flamingos and Great White Pelicans (Pelecanus onocrotalus). In addition, a high species richness of mammals, the hot springs, and scenery of the lakes all occur in the protected area [26]. The Park is a candidate wetland of international importance under the Ramsar Convention [24].

Little research has been conducted on the diversity and ecology of avian species in Ethiopia [27]. For instance, the status of the flamingo in Ethiopia has not been well known and the current populationstatus and habitat preference of flamingos in the area are poorly known. Likewise, data on diurnal and seasonal activity pattern of the species are scarce and this leads to the misunderstanding of how flamingos use local wetlands during the different seasons. The present study gives data on the population status of the two species, habitat preference, and their activity pattern in the Park.

\section{Materials and Methods}

2.1. The Study Area. Abijata-Shalla Lakes region was established as a National Park by the Ethiopian Wildlife Conservation Organization in 1970 with the aim of conserving the biodiversity of the spectacular number of aquatic birds [28]. The park is known as Abijata-Shalla Lakes National Park (ASLNP), deriving its name from the two Lakes Abijata and Shalla [24]. ASLNP is one of Ethiopia's National Parks, located in the Great Rift Valley comprising three lakes: Abijata, Shalla, and Chitu (Figure 1). The site lies between the $7^{\circ} 15-^{\prime} 7^{\circ} 45^{\prime} \mathrm{N}$ and $38^{\circ} 30^{\prime}-38^{\circ} 45^{\prime} \mathrm{E}$, at about $207 \mathrm{~km}$ south of Addis Ababa. ASLNP comprises two types of ecosystems, namely, the water part and land together covering a total area of $887 \mathrm{~km}^{2}$ of which $405 \mathrm{~km}^{2}$ is land area while $482 \mathrm{~km}^{2}$ is water body [29].

Among the three saline lakes in the National Park, Lake Shalla is the deepest ( $266 \mathrm{~m}$ deep) and covering an area of $370 \mathrm{~km}^{2}$ and Abijata is the shallowest ( $<7 \mathrm{~m}$ deep) and covering an area of $180 \mathrm{~km}^{2}$ [30]. Lake Chitu is the smallest covering an area of $0.8 \mathrm{~km}^{2}$ and a maximum depth of $21 \mathrm{~m}$ 


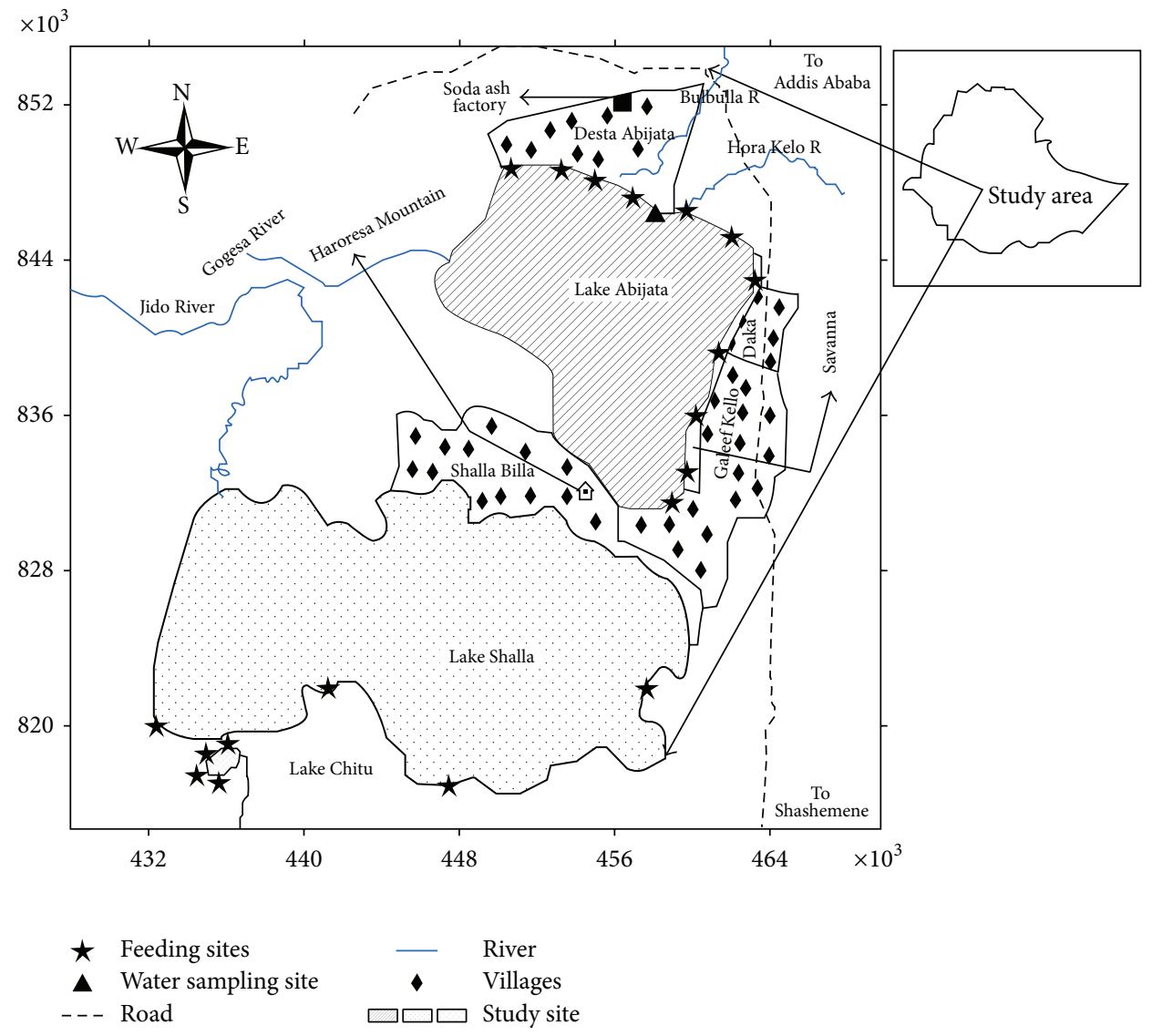

FIgURE 1: Map of the study area with study sites.

and is highly saline. Due to its location in a rainfall deficit area of the Rift Valley, ASLNP receives an annual rainfall ranging between 500 and $700 \mathrm{~mm}$ and the mean monthly temperature varies from $18.5^{\circ} \mathrm{C}$ to $24.6^{\circ} \mathrm{C}$ with mean annual temperature of $21^{\circ} \mathrm{C}$ [29]. The habitat surrounding the lakes in the park is generally dominated with tree species of Acacia and open scrub rocky slopes [29]. A total of 453 bird species have been recorded in the park [31]. The park has 6 endemic species to Ethiopia [28] and holds at least 144 and 292 water-associated and terrestrial bird species, respectively [29].

The study was carried out from 2011 to 2013. A total of 28 surveys were conducted throughout the study period on foot. Fourteen were performed during the rainy season (June to September) and the remaining fourteen during the dry seasons (November to May). Surveys of the three lake areas were conducted seasonally to identify and count the presence of individuals of both flamingo species. During the terrestrial surveys, depending on the size and shape of the wetland, 5 or more survey points per lake (in total 36 points) were taken and systematically all individual flamingos were recorded by direct count using telescopes (W30x or W22x), binoculars $(10 \times 42)$, and manual counters. Point-count method was conducted at four locations for 20 minutes in a point using direct observation through binoculars and telescopes [32]. The mean distance between observers and focal birds was
$45 \mathrm{~m}$. For a given wetland, the same census points were used during each subsequent survey as adopted by [33]. The size of the census area varied from point to point. The limits of subareas were determined beforehand and, in order to avoid double counts, moved to the next point as rapidly as possible without disturbing the birds. Habitat preference of the bird species is recorded by the observer each time birds were detected. For this purpose, onshore, mudflat and offshore categories were used.

At the time of census, reference points were established to enable flock identification when counting to avoid repetitions [34]. Flocks were defined as groups of flamingos in which the nearest-bird distance averaged $<25 \mathrm{~m}$, and where no bird was $>50 \mathrm{~m}$ from the nearest flock member as adopted by Bildstein et al. [35]. For larger number of birds ( $>4,000$ birds), poor visibility, or both, we counted birds in estimated groups (that is, 10, 100 [32]. Each count was done by at least two people, and the average was used as the estimated abundance. The census was conducted by 10 to 16 people recording the data together according to the size of the site and bird settlement. Multi-lake censuses were conducted over short periods of time at the same time.

To minimize disturbance during counting, silent movement followed by 3 to 5 minutes of waiting period was allowed to settle down from any disturbance [32]. Census data were 
TABLE 1: Number of Lesser and Greater Flamingos on lakes censused from 2011 to 2013.

\begin{tabular}{|c|c|c|c|c|c|c|c|c|c|c|}
\hline \multirow{4}{*}{ Site } & \multicolumn{8}{|c|}{ Species with season } & \multirow{2}{*}{\multicolumn{2}{|c|}{ Mean \pm SE }} \\
\hline & \multicolumn{4}{|c|}{ 2011-2012 } & \multicolumn{4}{|c|}{$2012-2013$} & & \\
\hline & \multicolumn{2}{|c|}{ Wet } & \multicolumn{2}{|c|}{ Dry } & \multicolumn{2}{|c|}{ Wet } & \multicolumn{2}{|c|}{ Dry } & \multirow[b]{2}{*}{$\mathrm{L}$} & \multirow[b]{2}{*}{ G } \\
\hline & $\mathrm{L}$ & G & $\mathrm{L}$ & G & $\mathrm{L}$ & G & $\mathrm{L}$ & G & & \\
\hline \multicolumn{11}{|l|}{ Abijata Lake } \\
\hline Bulbulla and Hora Kelo rivers inlet & 9200 & 278 & 29700 & 847 & 15535 & 534 & 22173 & 464 & $19152 \pm 19.6$ & $530.75 \pm 11.7$ \\
\hline Gogesa River & 345 & 11 & 2956 & 245 & 482 & 18 & 1115 & 92 & $1224.5 \pm 9.5$ & $91.5 \pm 4.2$ \\
\hline Savanna & 652 & - & 3516 & - & 1130 & - & 2448 & - & $1936.5 \pm 12.6$ & - \\
\hline Haroresa mountain & 71 & - & 441 & - & 168 & - & 186 & - & $216.5 \pm 8.2$ & - \\
\hline Fresh artificial pond of soda ash factory & 634 & - & 2325 & - & 413 & - & 1678 & 14 & $1262.5 \pm 14.2$ & $3.5 \pm 0.3$ \\
\hline Total & 10902 & 289 & 38938 & 1092 & 17728 & 552 & 27600 & 570 & $23792 \pm 15$ & $625.75 \pm 11$ \\
\hline Lake Shalla & 16300 & 1008 & 7200 & 906 & 19058 & 3819 & 6267 & 548 & $12206.25 \pm 4.3$ & $1570.25 \pm 9.3$ \\
\hline Lake Chitu & 17812 & 189 & 13153 & 313 & 18513 & 493 & 11312 & 123 & $15197.5 \pm 9.6$ & $279.5 \pm 5.1$ \\
\hline Total & 45014 & 1486 & 59291 & 2311 & 55299 & 4864 & 45179 & 1241 & $51195.75 \pm 13.4$ & $2475.5 \pm 7$ \\
\hline
\end{tabular}

L: Lesser Flamingo; G: Greater Flamingo.

collected twice a day, morning (6:30-10:00 a.m.) and late afternoon (10:00 to 6:00 p.m.). These were the periods when most avian species were most active [36].

Various activity patterns of nonbreeding flamingos were recorded during dry and wet seasons of each year at Lake Abijata. Behavioral observations were conducted randomly in two distinct points where flamingos were most numerous. Observations were made using binoculars, at least $35 \mathrm{~m}$ from the birds to avoid interference. Since no breeding was observed in the lakes, behaviors associated with the breeding period, such as courting, copulation, and incubation, were not observed. Behaviors were recorded using scan sampling techniques [37] because flock activities of flamingos often are synchronized [38]. Sampling was conducted on three randomly selected days per week with each day divided into four equal time blocks of (1) early morning (06:00-09:00 hr), (2) late morning (09:00-12:00 hr), (3) midday (12:00-14:00), and (4) late afternoon/evening (15:00-18:00) as adopted by Lehner [39]. Data were collected from September 10-14, 2011 (on 4 separate days), October 20-23, 2011 (on 3 days), February 21-27, 2012 (on 6 days), August 12-18, 2012 (on 6 days), March 17-21, 2013 (on 5 days), and May 27-29, 2013 (on 2 days). A total of $303 \mathrm{~h}$ of observation was carried out during the hours from 06:00 to 18:00. Each individual of flock was observed for $2 \mathrm{~min}$ (focal animal analysis) as used by Altman [37]. The time spent in different activities was calculated and from these values the percentage time spent for each activity during different times on the day was estimated. The activities are divided into five categories as follows:

(i) feeding: stand feeding and walk feeding (feeding was defined as a flamingo holding its head down with the beak either partially or totally submerged),

(ii) moving (walking, swimming, and flight),

(iii) resting (standing, sleep, and grooming),

(iv) preening (feather shaking, wing flapping, tail shaking, and bath),

(v) alert (alarm) [38].
To analyze the data Stata version 12 software was used. ANOVA and chi-square test were performed to find out statistically significant difference among various variables. Behavior data were analyzed with a Kruskal-Wallis test, a nonparametric test.

\section{Result}

3.1. Population and Habitat Preference of Flamingo. A total of 53671 individuals representing two species of birds were counted during both wet and dry seasons from the three lakes. Lesser Flamingos were the most abundant comprising 95.39\%, while Greater Flamingos comprised 4.61\%. These constituted $50.32 \%$ of the total species during the dry season and $49.68 \%$ during the wet season count. There were more flamingos during the dry season than the wet season in Lake Abijata $\left(x^{2}=10.31, \mathrm{df}=1, P<0.05\right)$. The wet season count significantly outnumbered the dry season count in Lake Shalla $\left(x^{2}=34.15, \mathrm{df}=1, P<0.05\right)$ and Lake Chitu $\left(x^{2}=3.76, \mathrm{df}=1, P<0.05\right)$. The difference was also significant between lakes $\left(x^{2}=24.83, \mathrm{df}=2, P<0.05\right)$ (Table 1).

From the total population, Lake Abijata harbors $46.47 \%$ and $25.28 \%$ Lesser and Greater Flamingos, respectively, and Lake Shalla supports $23.84 \%$ lesser and $63.43 \%$ Greater Flamingo, whereas Lake Chitu supports $29.68 \%$ and $11.29 \%$ of Lesser and Greater flamingos, respectively. Lake Abijata is the major stronghold of Lesser Flamingos in the area. There was significant variation in the mean number of Lesser Flamingo $\left(F_{4101}=110.42, P<0.005\right)$ and Greater Flamingo $\left(F_{4101}=\right.$ 130.16, $P<0.005)$ during the wet and dry season in the different study sites of the lake, respectively. For both species, the highest record was obtained during the dry season in Bulbulla and Hora Kelo rivers inlet site and the lowest was in Haroresa mountain site for Lesser Flamingo and Savanna and Haroresa mountain sites for Greater Flamingo as represented in Table 1. 


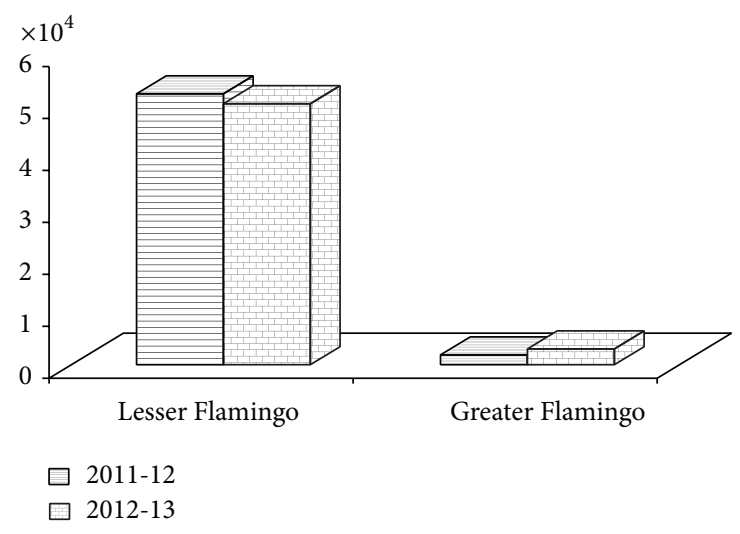

FIgURE 2: Mean number of Lesser and Greater Flamingos from 2011 to 2013 on the whole study sites.

There was no significant difference in the mean number of Lesser Flamingos of the two-year period on the three lakes $\left(x^{2}=1.13, \mathrm{df}=1, P>0.05\right)$. However, the count of Greater Flamingo showed a significant variation among years $\left(x^{2}=\right.$ $0.36, \mathrm{df}=1, P<0.05$ ) (Figure 2). The highest record of Lesser Flamingo was obtained during 2011-2012 year count, while, for Greater Flamingo, the highest record was during 20122013 count.

The largest average flock size was for the Lesser Flamingos (10,000 birds) and for Greater Flamingos (14 birds). Lesser Flamingo flocks consisted of greater than 500 birds that are very common and flocks of less than 20 birds that are rare. Seasonal average flock sizes were not similar between the species (Table 2). Flock sizes were the largest during the wet season for both species and were significantly different across seasons, for Lesser Flamingos $\left(x^{2}=4.14, \mathrm{df}=1, P<0.05\right)$ and for Greater Flamingos $\left(x^{2}=1.11, \mathrm{df}=1, P<0.05\right)$.

Flamingos were observed in various parts of the lakes during the day. At Lake Abijata, birds were mainly observed along the northwest of the lake during early morning. During the late afternoon, they flew in flocks to the northeastern side and continue feeding during the course of the day. At night, most birds roost back in the northwest side of the lake. Lesser Flamingos were more frequent in shallow area of the lakes and mudflats, occasionally preferring man-made solar salt concentration ponds of Soda ash factories. Lesser Flamingos in Lake Chitu were most of the time concentrated on the southern and western side of the lake shore in relation to human disturbance.

The relative use of the different habitats by flamingo was statistically significant $\left(F_{463}=18.49, P<0.005\right)$ as indicated in Figure 3. Lesser Flamingo showed a very high $(65.91 \%)$ utilization on the shore line. This utilization of habitat by the Lesser Flamingo was very different from the habitat preference of Greater Flamingo (59.76\%) which utilized offshore area of the lakes.

3.2. Activity Patterns. The data from Table 3 are used to show different activities of nonbreeding Lesser Flamingo. There was a strong relationship between time allocated to

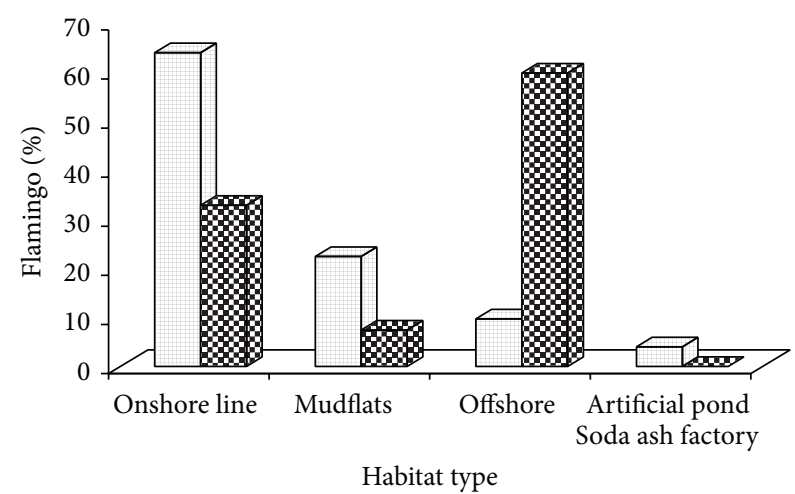

$\square$ Lesser Flamingo
$\bigotimes$ Greater Flamingo

Figure 3: Percentage of flamingos observed at different habitat types.

TABLE 2: Group size of lesser and greater flamingos in the lakes.

\begin{tabular}{lcccc}
\hline Species & Season & Groups & Group size range & $\begin{array}{c}\text { Mean } \\
\text { group size }\end{array}$ \\
\hline \multirow{2}{*}{ Lesser flamingo } & Dry & 52 & $2-4400$ & 2100 \\
& Wet & 112 & $2-10,000$ & 7300 \\
Greater flamingo & Dry & 26 & $2-18$ & 15 \\
& Wet & 15 & $2-34$ & 27 \\
\hline
\end{tabular}

each activity and time of day. Feeding activity varied among daylight hours and was higher in the evening (76.5\%) and late morning (74.56\%) than least during midday (54\%). The peaks in moving were similar to the peaks in feeding during all the time blocks of a day and preening and resting were higher during the midday.

Percent time spent in all activity differed significantly except alerting. On average, $68.35 \%$ of the bird day time was spent in feeding. Feeding occurred all hours but there was a reduction in feeding activity between 1200 and 1500 hours. Percent time spent in feeding, resting, and preening differed significantly based on seasons (Table 4 ). Lesser Flamingos fed least during the dry season $(62.33 \%)$ and most during the wet season (77.91\%). Preening activities occurred more during the wet season than the dry season. Alerting and moving showed insignificant variation in season. Resting activity varied between time of day and season. It always peaked during midday and the dry season.

\section{Discussion}

Flamingos typically are the most prominent and important consumers in the lakes. The largest concentration of flamingo was 24,417 in Lake Abijata. However, drastic and sudden fluctuations in number can occur and there is a very marked exchange between the lakes. There were more flamingos during the dry season than the wet season in Lake Abijata and contrary to Lakes Shalla and Chitu during the wet season. Despite the observed fluctuations, the total flamingo population of the area remained relatively stable, suggesting that 
TABLE 3: Percentage of time spent (mean \pm SD) on different activities by nonbreeding lesser flamingos based on time of day.

\begin{tabular}{lcccccc}
\hline \multirow{2}{*}{ Activity } & \multicolumn{5}{c}{ Time of the day (hours) } \\
& $0600-0900$ & $0900-1200$ & $1200-1500$ & $1500-1800$ & $H$ \\
\hline Feeding & $68.33 \pm 7.21$ & $74.56 \pm 4.2$ & $54 \pm 3.2$ & $76.5 \pm 4.5$ & 51.12 \\
Moving & $6.5 \pm 5.11$ & $7.17 \pm 1.43$ & $3.95 \pm 0.21$ & $10.67 \pm 0.6$ & 78.13 \\
Resting & $8.83 \pm 2.3$ & $2.1 \pm 0.3$ & $20.55 \pm 1.4$ & $3.83 \pm 0.2$ & 42.11 & $0.000^{*}$ \\
Preening & $10.01 \pm 3.4$ & $8.67 \pm 2.03$ & $17.5 \pm 2.1$ & $2.33 \pm 1.3$ & 28.34 & $0.000^{*}$ \\
Alerting & $6.33 \pm 1.62$ & $7.5 \pm 072$ & $4 \pm 0.78$ & $6.67 \pm 0.4$ & 16.47 \\
\hline
\end{tabular}

${ }^{*}$ Differ significantly (Kruskal-Wallis test, $P<0.05$ ) between time blocks.

TABLE 4: Percentage of time spent (mean \pm SD) on different activities by nonbreeding lesser flamingos based on seasons.

\begin{tabular}{lcccc}
\hline \multirow{2}{*}{ Activity } & \multicolumn{2}{c}{ Season } & $H$ & $P$ \\
& Dry & Wet & & \\
\hline Feeding & $62.33 \pm 3.1$ & $77.91 \pm 2.4$ & 37.23 & $0.000^{*}$ \\
Moving & $5.27 \pm 2.3$ & $7.11 \pm 1.4$ & 7.21 & 0.121 \\
Resting & $18.74 \pm 1.7$ & $1.27 \pm 0.4$ & 22.3 & $0.000^{*}$ \\
Preening & $5.36 \pm 0.6$ & $10.90 \pm 2.2$ & 27.12 & $0.000^{*}$ \\
Alerting & $8.3 \pm 1.3$ & $2.81 \pm 0.3$ & 3.45 & 0.141 \\
\hline
\end{tabular}

${ }^{*}$ Differ significantly (Kruskal-Wallis test, $P<0.05$ ) between seasons.

the flamingos responded to the effect of seasonal variation by moving between lakes. This aspect of behavior makes flamingos nonresident in any one saline lake, moving and exploiting various nearby lakes as their home range [40]. A seasonal pattern of abundance was observed which was positively correlated with weather and water level quality has been shown for many species of flamingos [41]. The algal food resources are not stable and decline from time to time [42]. Hence, any lake that provides food in suitable quality and quantity makes a valuable contribution to the survival of these birds. Therefore, seasonal abundance of diet might be the primary cause for the difference in the number of individuals within and among lakes. Diet abundance within lakes is associated with variations of water characteristics like conductivity and salinity [43].

The relative difference in the number of flamingos in Lake Abijata sites might be due to the difference in quantity of their diet among sites. In particular, differences in concentration of flamingos at the rivers inlet sites might be due to the concentration of algae as a result of fresh water nutrients provided by the rivers for algal growth and access to use the fresh water to drink. Vareschi [14] and Tuite [41] stated a striking characteristic of flamingos to strong fluctuations on Rift Valley Soda Lakes. Variations could also be caused by availability of fresh water [44].

The Greater Flamingos which occur at low density in the same habitat with the Lesser Flamingo are mostly found (63\%) in Lake Shalla. This might be related to the feeding habit of the birds. Greater Flamingos are generalists consuming copepods, mollusks, and other small planktonic and benthic animals in addition to algae [4]. Greater Flamingos feed mainly on invertebrates which they filter from water or mud over a large range of habitats [45]. Shalla has poor phytoplankton and yet supports dense number of benthic organisms [46].
Flamingos are gregarious birds and form very large feeding groups. They form large foraging flocks, which can be interpreted as a consequence of the high patchiness of food distribution. On several occasions, Greater Flamingos showed preference to offshore area of the lakes. In contrast, Lesser Flamingo mainly preferred the shoreline and mudflat of the lakes. This preference for shallow water bodies may be related to the species' foraging behavior, characterized by feeding on small diatoms and Spirulina near the lake banks. Lesser Flamingos require shallow eutrophic wetlands and waterbodies which are more saline than those used by the Greater Flamingos, because it feeds mainly blue-green algae that bloom under these conditions [47]. During the wet season, Lesser Flamingos at Lake Abijata were observed in mudflat habitat where diatoms may be plentiful [48].

Feeding usually was the major activity of flamingo, probably because of the small size of their prey items that flamingos are forced to spend more time on feeding than on other forms of behavior. More feeding activity of flamingo in the late afternoon may reflect their need to obtain energy for overnight energetic requirements. The general pattern of flamingo feeding in different regions worldwide is that they fed mainly during morning and late afternoon to early evening and roosted during the midday [35]. The rate of resting was the highest in the middle of the day, between 012:00 and 15:00. Probably, the main purpose of this rest is to avoid the heat of the day to conserve water loss. Flamingos spend more time in feeding activities during the wet than dry seasons. There are several possible explanations. It is their breeding season which necessitates an increase in forage intake regardless of the ambient conditions. However, the main effect was the decline of availability of their diet in the area (Lake Abijata) during wet season [48]. Preening showed a significant variation with season and time of a day (high during midday and low during late afternoon). It plays an important role in deparasitisation and feather adjustment [49]. Similar to preening, moving showed marked seasonal and time of day changes. Individuals spent more time moving in the afternoon partly because a fraction of the population left the site to go to another one after having taken the required food intake and also disturbance by raptors (African fish eagle) occurs mainly in the afternoon.

\section{Conclusion}

Seasonal and annual fluctuations are observed in the total number of birds counted. Such changes in flamingo counts 
at individual lakes may indicate changes in the importance of each of these Soda lakes both within years and between years. The distribution and abundance of flamingos are related to food supply. Thus, changes in the numbers of flamingos at a particular lake during the year and between years may reflect fluctuations in the availability of food supply and may at least in part be a result of anthropogenic activities. Conservation efforts in the park should include not only the wild flora and fauna not only of the land but also of the aquatic systems because both places represent one integrated system. Presently, there is no effective protection of flamingo feeding areas or enforcement of laws protecting the bird. Ethiopian Wildlife Conservation Authority should take a more positive position action to protect flamingos.

\section{Conflict of Interests}

The authors declare that there is no conflict of interests regarding the publication of this paper.

\section{Acknowledgments}

The authors wish to thank Addis Ababa University and Animal Diversity Research Project for providing the required facilities for carrying out the above research work.

\section{References}

[1] J. del Hoyo, A. Elliot, and J. Sargatal, Handbook of the Birds of the World, vol. 1 of Ostrich to Ducks, Lynx Edicions, Barcelona, Spain, 1992.

[2] M. A. Ogilvie and C. Ogilvie, Flamingos, Alan Sutton Publishing, Gloucester, UK, 1986.

[3] C. Mlingwa and N. Baker, "Lesser Flamingo Phoenconaias minor counts in Tanzanian soda lakes," in Implications for Conservation, G. C. Boere, C. A. Galbraith, and D. A. Stroud, Eds., pp. 260-267, The Stationery Office, Edinburgh, Scotland, 2006.

[4] B. Childress, S. Nagy, and B. Hughes, International Single Species Action Plan for the Conservation of the Lesser Flamingo (Phoeniconaias Minor), AEWA Technical Series, no. 34, Agreement on the Conservation of African-Eurasian Migratory Waterbirds, Bonn, Germany, 2008.

[5] S. Delany and D. Scott, Waterbird Population Estimates, Wetlands International, Wageningen, The Netherlands, 2006.

[6] K. Unger and J. J. Elston, "Successful ex-situ breeding of lesser flamingo (Phoeniconaias minor)," in Flamingo Bulletin of the IUCE-SSC-Wetlands International Flamingo Specialist Group, B. Childress, F. Arengo, and A. Bechet, Eds., no. 17, pp. 64-67, Wildfowl \& Wetlands Trust, Slimbridge, UK, 2009.

[7] A. R. Johnson, F. Cezilly, and V. Boy, "Plumage development and maturation in the greater flamingo Phoenicopterus ruber," Ardea, vol. 81, pp. 25-34, 1993.

[8] L. Krienitz, P. K. Dadheech, and K. Kotut, "Mass developments of a small sized ecotype of Arthrospira fusiformis in Lake Oloidien, Kenya, a new feeding ground for lesser flamingos in east Africa," Fottea, vol. 13, pp. 215-225, 2013.

[9] A. R. Johnson and F. Cezilly, The Greater Flamingo, T. \& A. D. Poyser, London, UK, 2007.
[10] R. E. Simmons, "Population declines, viable breeding areas, and management options for flamingos in southern Africa," Conservation Biology, vol. 10, no. 2, pp. 504-514, 1996.

[11] O. Nasirwa, "Conservation status of flamingos in Kenya," Waterbirds, vol. 23, pp. 47-51, 2000.

[12] R. E. Simmons, "Declines and movements of Lesser Flamingos in Africa," Waterbirds, vol. 23, pp. 40-46, 2000.

[13] T. P. Boyle, S. M. Caziani, and R. G. Waltermire, "Landsat TM inventory and assessment of waterbird habitat in the southern altiplano of South America," Wetlands Ecology and Management, vol. 12, no. 6, pp. 563-573, 2005.

[14] E. Vareschi, "The ecology of Lake Nakuru (Kenya). I. Abundance and feeding of the lesser flamingo," Oecologia, vol. 32, no. 1, pp. 11-15, 1978.

[15] C. H. Tuite, "Population size, distribution and biomass density of the Lesser Flamingo in the Eastern Rift Valley, 1974-1976," Journal of Applied Ecology, vol. 16, no. 3, pp. 765-775, 1979.

[16] B. Childress, "New flamingo population estimates for Africa and Southern Asia," in Flamingo, Bulletin of the IUCNSSC/Wetlands International Flamingo Specialist Group, B. Childress, A. Béchet, F. Arengo, and N. Jarrett, Eds., no. 13, pp. 18-21, Wildfowl \& Wetlands Trust, Slimbridge, UK, 2005.

[17] L. A. Bennun, "Threats to lesser flamingos in East Africa," in Conservation of the Lesser Flamingo in Eastern Africa and Beyond, G. W. Howard, Ed., pp. 31-33, IUCN East Africa Programme, Lake Bogoria Conference, Nairobi, Kenya, 1994.

[18] O. Balkiz, A. Béchet, L. Rouan et al., "Experience-dependent natal philopatry of breeding greater flamingos," The Journal of Animal Ecology, vol. 79, no. 5, pp. 1045-1056, 2010.

[19] N. Baccetti, L. Panzarin, F. Cianchi, L. Puglisi, M. Basso, and E. Arcamone, "Two new greater flamingo (Phoenicopterus roseus) breeding sites in Italy," in Flamingo, Bulletin of the IUCN-SSC/Wetlands International Flamingo Specialist Group, B. Childress, F. Arengo, and A. Bechet, Eds., no. 16, pp. 24-27, Wildfowl \& Wetlands Trust, Slimbridge, UK, 2008.

[20] M. Smart, H. Azafzaf, and H. Dlensi, "Analysis of the mass of raw data on Greater Flamingos Phoenicopterus roseus on their wintering grounds, particularly in North Africa," in Flamingo, Bulletin of the IUCNSSC/ Wetlands International Flamingo Specialist Group, Special Publication 1: Proceedings of the 4th International Workshop on the Greater Flamingo in the Mediterranean Region and Northwest Africa, A. Béchet, M. Rendón-Martos, J. Amat, N. Baccetti, and B. Childress, Eds., pp. 58-61, Wildfowl \& Wetlands Trust, Slimbridge, UK, 2009.

[21] B. Childress, B. Hughes, D. Harper, and W. van den Bossche, "East African flyway and key site network of the Lesser Flamingo (Phoenicopterus minor) documented through satellite tracking," Ostrich, vol. 78, no. 2, pp. 463-468, 2007.

[22] R. Koenig, "The pink death: die-offs of the lesser flamingo raise concern,” Science, vol. 313, no. 5794, pp. 1724-1725, 2006.

[23] BirdLife International, "Phoeniconaias minor," IUCN red list of threatened species, 2008, http://www.iucnredlist.org.

[24] EWNSH, Important Bird Areas of Ethiopia: A First Inventory, Ethiopian Wildlife and Natural History Society, Addis Ababa, Ethiopia.

[25] J. G. Stephenson, An Appraisal of the Conservation of Nature in the Lakes Abijiata and Shalla Locality with Recommendations, Ethiopian Wildlife Conservation Organisation, Addis Ababa, Ethiopia, 1978.

[26] EWNHS, Important Bird Areas Program Site Account: AbijataShalla Lakes National Park, Ethiopia Wildlife and Natural History Society, Addis Ababa, Ethiopia, 2000. 
[27] J. S. Ash and T. M. Gullick, “The present situation regarding endemic breeding birds of Ethiopia," Scopus, vol. 13, pp. 90-96, 1989.

[28] J. C. Hillman, Ethiopia: Compendium of Wildlife Conservation Information, vol. 1 \& 2, New York Zoological Society, The Wildlife Conservation Society International, New York, NY, USA; Ethiopian Wildlife Conservation Organization, Addis Ababa, Ethiopia, 1993.

[29] F. Senbeta and F. Tefera, "Environment crisis in the AbijiataShalla Lakes national park," Walia, vol. 22, pp. 1-13, 2001.

[30] T. Ayenew, "Environmental implications of changes in the levels of lakes in the Ethiopian Rift since 1970," Regional Environmental Change, vol. 4, no. 4, pp. 192-204, 2004.

[31] R. Almaw, A Checklist of the Birds of the Abijata-Shalla Lakes National Park (Central Rift Valley), Ethiopian Wildlife Conservation Authority, Addis Ababa, Ethiopia, 2012.

[32] C. Bibby, N. D. Burgess, and D. A. Hill, Bird Census Techniques, Academic Press, London, UK, 1992.

[33] W. J. Sutherland, Ecological Census Techniques: A Handbook, Cambridge University Press, London, UK, 1996.

[34] N. D. Niemuth, M. E. Estey, R. E. Reynolds, C. R. Loesch, and W. A. Meeks, "Use of wetlands by spring-migrant shorebirds in agricultural landscapes of North Dakota's drift prairie," Wetlands, vol. 26, no. 1, pp. 30-39, 2006.

[35] K. L. Bildstein, P. C. Frederick, and M. G. Spalding, "Feeding patterns and aggressive behavior in juvenile and adult American flamingos," The Condor, vol. 93, no. 4, pp. 916-925, 1991.

[36] W. J. Sutherland, The Conservation Handbook Research Management and Policy, Cambridge University Press, Cambridge, UK, 2000.

[37] J. Altmann, "Observational study of behavior: sampling methods," Behaviour, vol. 49, no. 3, pp. 227-267, 1974.

[38] M. P. Kahl, "Distribution and numbers a summary," in Flamingos, J. Kear and H. Duplaix-Hall, Eds., pp. 93-149, T. \& A. D. Poyser, Berkhamsted, UK, 1975.

[39] P. N. Lehner, Handbook of Ethological Methods, Cambridge University Press, Cambridge, UK, 2nd edition, 1996.

[40] G. McCulloch, A. Aebischer, and K. Irvine, "Satellite tracking of flamingos in southern Africa: the importance of small wetlands for management and conservation," Oryx, vol. 37, no. 4, pp. 480$483,2003$.

[41] C. H. Tuite, "The distribution and density of Lesser Flamingos in east Africa in relation to food availability and productivity," Waterbirds, vol. 23, pp. 52-63, 2000.

[42] E. Vareschi and J. Jacobs, "The ecology of Lake Nakuru. VI. Synopsis of production and energy flow," Oecologia, vol. 61, pp. 70-82, 1985.

[43] S. M. Caziani, O. R. Olivio, E. R. Ramírez et al., "Seasonal distribution, abundance, and nesting of Puna, Andean, and Chilean flamingos," The Condor, vol. 109, no. 2, pp. 276-287, 2007.

[44] E. Vareschi, "The ecology of Lake Nakuru (Kenya). III. Abiotic factors and primary production," Oecologia, vol. 55, no. 1, pp. 81-101, 1982.

[45] G. Zweers, F. de Jong, and H. Berkhoudt, "Filter feeding in flamingos (Phoenicopterus ruber)," Journal of Avian Biology, vol. 97, pp. 1-28, 1995.

[46] C. Tudorancea and A. D. Harrison, "The benthic communities of the saline lakes: Abijata and Shala (Ethiopia)," Hydrobiologia, vol. 158, no. 1, pp. 117-123, 1988.
[47] L. H. Brown, E. K. Urban, and K. Newman, The Birds of Africa, vol. I, Academic Press, London, UK, 1982.

[48] T. Kumssa and A. Bekele, "Phytoplankton composition andphysico-chemicalparameters study in water bodies of Abijata-Shalla Lakes National Park (ASLNP), Ethiopia," Greener Journal of Biological Sciences, vol. 4, no. 2, pp. 69-76, 2014.

[49] P. Cotgreave and D. H. Clayton, "Comparative analysis of time spent grooming by birds in relation to parasite load," Behaviour, vol. 131, no. 3-4, pp. 171-187, 1994. 

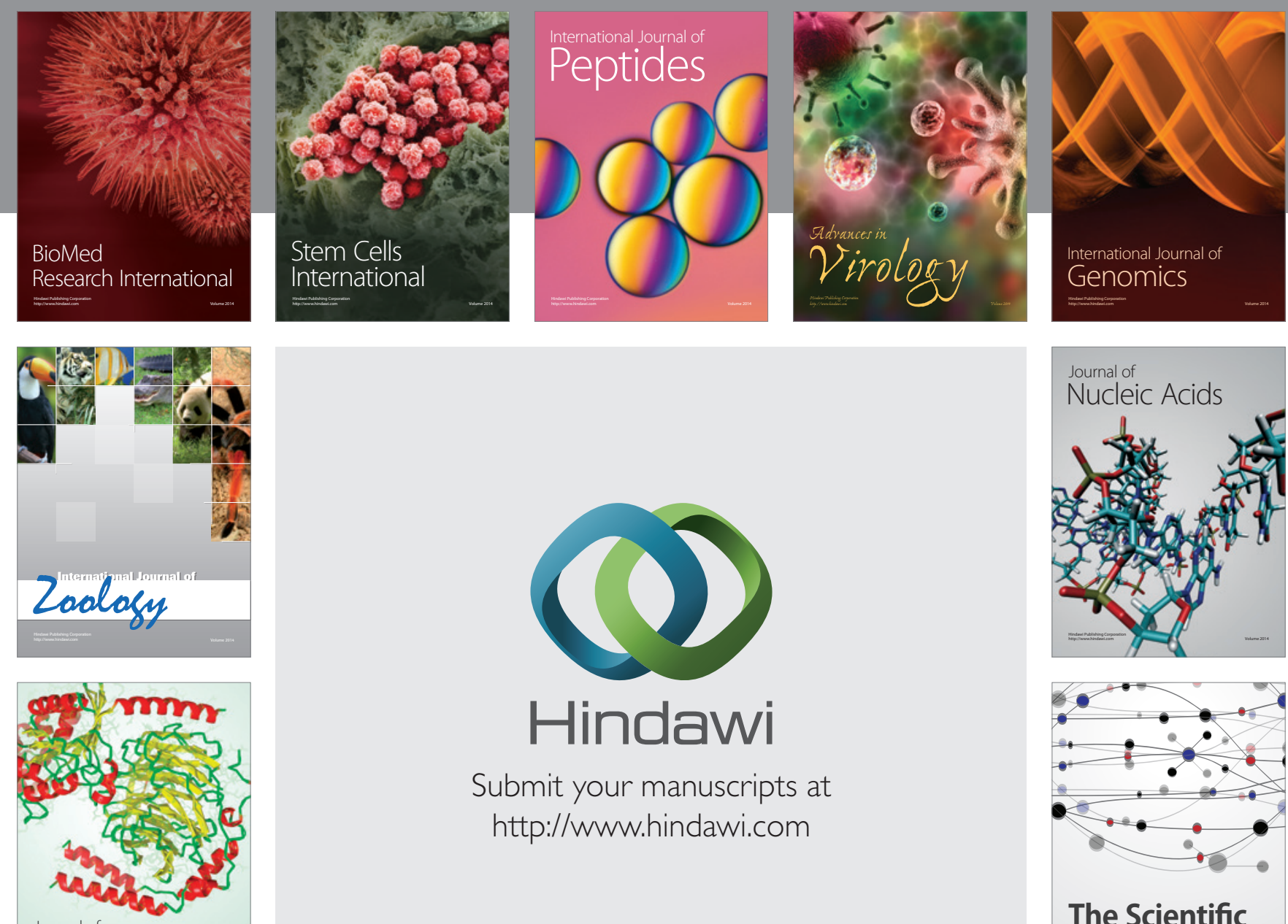

Submit your manuscripts at

http://www.hindawi.com

Journal of
Signal Transduction
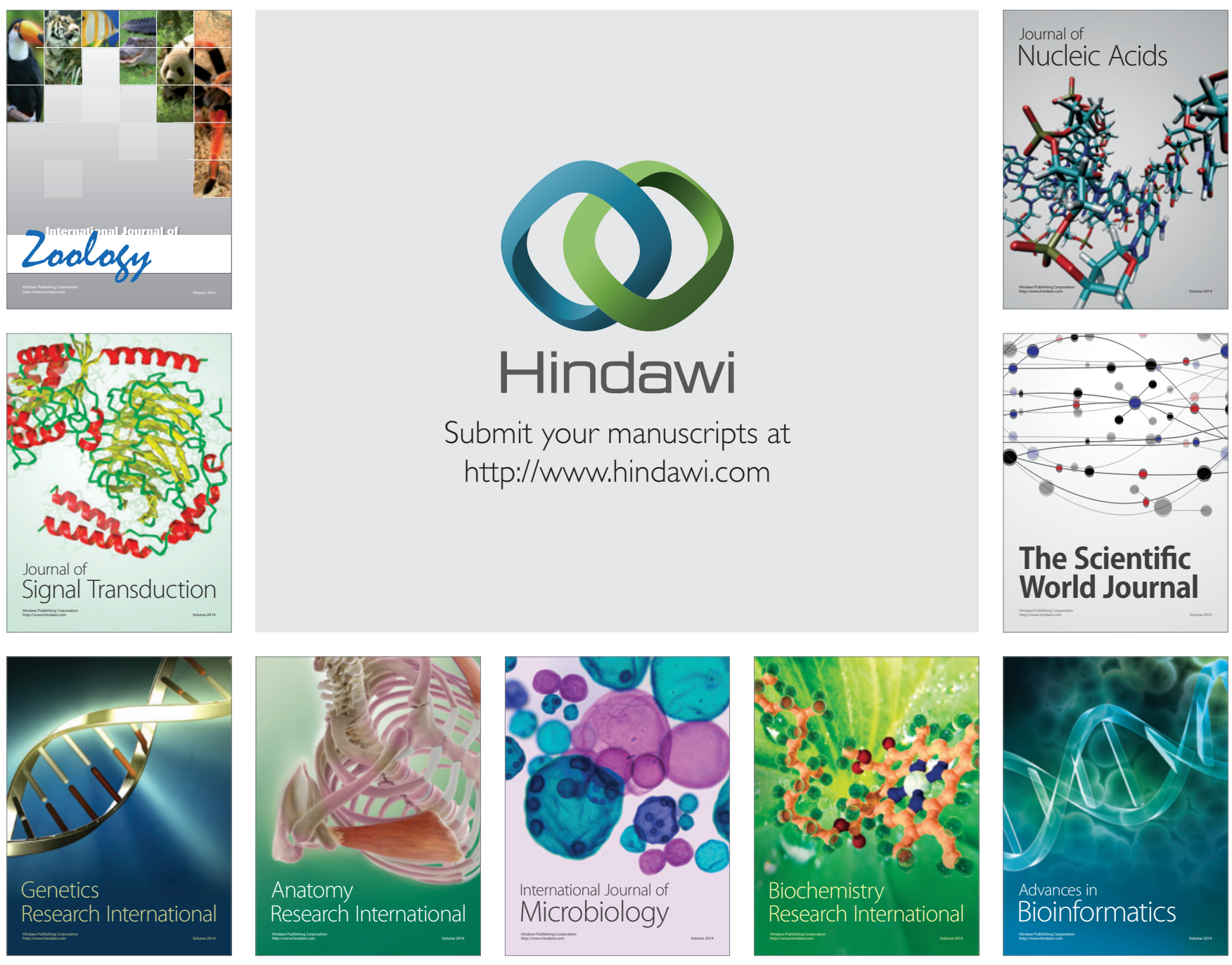

The Scientific World Journal
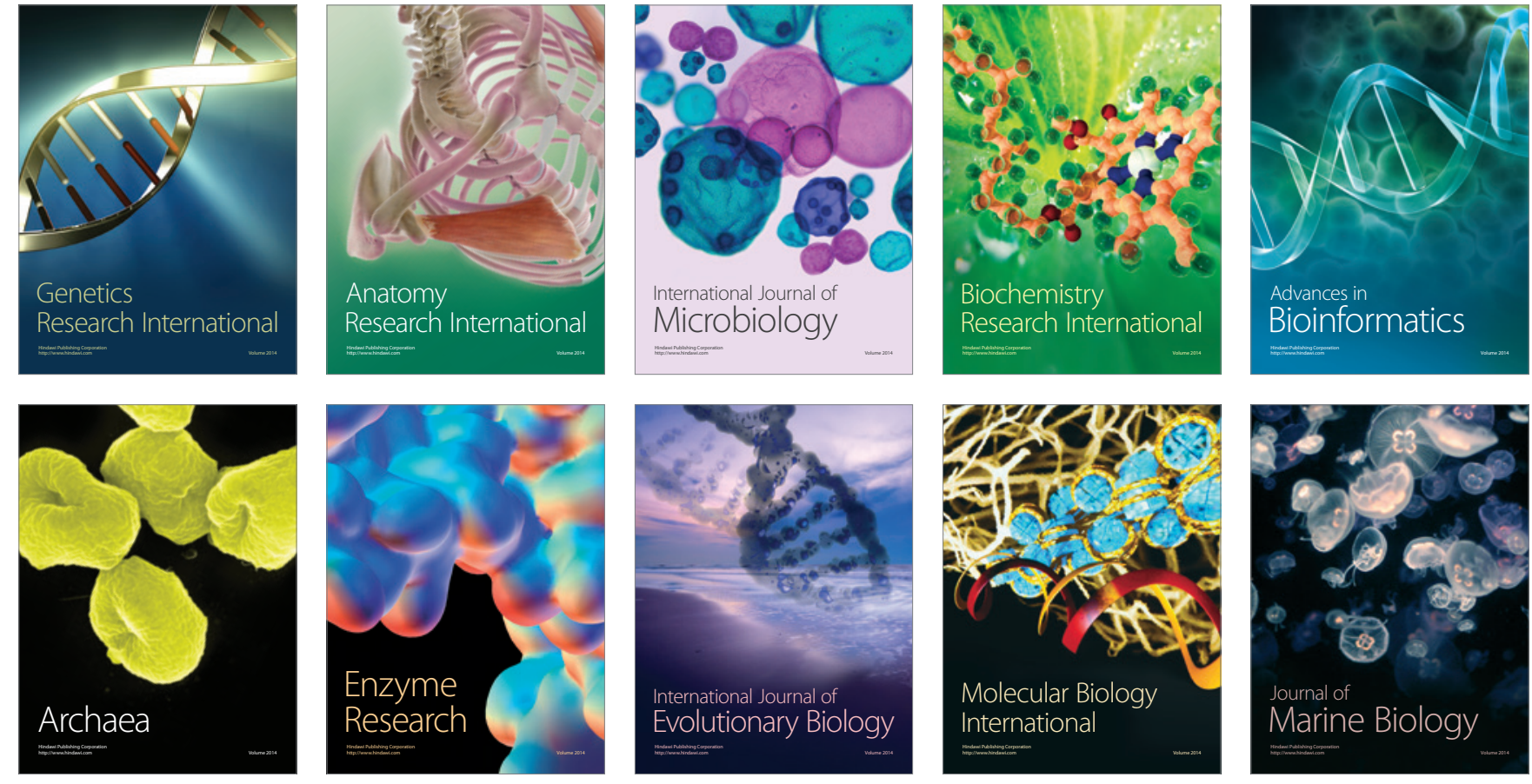